\title{
Analysis of the methods for assessing the quality of entrepreneurial education
}

\author{
Maria Vdovichenko ${ }^{1, *}$, Elena Lyapuntsova ${ }^{1}$, Yulia Belozerova $^{2}$, Ilona Drozdova ${ }^{3}$ \\ ${ }^{1}$ Bauman Moscow State Technical University, st. 2-Ya Baumanskaya, 5/1, Moscow, 105005, Russian \\ ${ }^{2}$ The Institute of cinema and TV (GITR) (ex named The Humanities Institute of TV and Radio \\ Broadcasting), 32A Khoroshevskoye road, Moscow, 123007, Russia \\ ${ }^{3}$ Federal State Educational Institute of High Education, Russian University of Transport, st. \\ Obraztsova 9/9, Moscow, 127994, Russian
}

\begin{abstract}
Improving the quality of education is becoming one of the main goals of the Ministry of Education of the Russian Federation, any reform in education is aimed at improving quality. To date, it has been proven that there is a direct relationship between entrepreneurship activity and entrepreneurship education. Every year the Ministry of Education creates new programs aimed at training enterprisers. The paper aims to study possible methods of independent quality assessment of entrepreneurship education. In the course of the research, mechanisms for monitoring the quality of entrepreneurship education were developed and proposed.
\end{abstract}

\section{Introduction}

In the last decade, the development of approaches to quality assessment of entrepreneurship education has been carried out through the system of all-Russian, regional and international monitoring of the quality of education, as well as through scientific and practical developments carried out both at the federal and regional levels.

The works of recent years $[1,2,3,4]$ reflect the world experience in developing a toolkit for assessing learning outcomes, including testing and processing results, based on modern theories of pedagogical measurements.

Within the framework of comprehensive projects for the modernization of education in the constituent entities of the Russian Federation (priority national project "Education"), work has begun on the formation of various models of regional systems of quality assessment of education under the Decree of the President of the Russian Federation of June 28, 2007. No. 825 "On the assessment of the activities of the executive authorities of the constituent entities of the Russian Federation."

The development of models of control over the observance by universities and branches of universities of the conditions of educational activities, provided for by the license, continues [7-10].

At the same time, the system of quality assessment of entrepreneurship education in Russia has just begun to be created, a unified conceptual and methodological understanding of the problems of education quality and approaches to its measurement has not yet been

\footnotetext{
*Corresponding author: mmvdovichenko@gmail.com
} 
formed. Quite often, untested and unstandardized toolkits are used [5,6,14]. The activities of various organizations dealing with problems of the quality of entrepreneurship education are not well coordinated. There is no necessary scientific and methodological support for an objective and reliable collection of information, there is a shortage of qualified personnel, the regulatory and legal framework of the system of quality assessment of education is poorly developed.

The solution to these problems requires purposeful efforts to form a general systematic approach to the quality assessment of entrepreneurship education as the basis of an integral all-Russian system of quality assessment of education.

Let us analyze the existing methods of quality assessment of entrepreneurship education [11-13].

\section{The internal quality assessment of education}

The internal quality assessment of in the entrepreneurship education system is built taking into account three main components of the educational process:

- trainees (learners, students);

- trainers (teachers, lecturers);

- resource support (organizational, material and technical, educational and methodological, informational, financial).

\subsection{Self-scoring of trainees}

In the context of continuous education, "education throughout life" [8], the ability to selfcontrol and self-scoring of one's educational activity becomes the most important quality for a person. The development of this component of the internal assessment should be implemented through the development of appropriate scientific and methodological support. This fully applies to the self-scoring of trainers, for example, teachers.

The subject of assessment is the object of assessment; closed arrow - self-scoring.

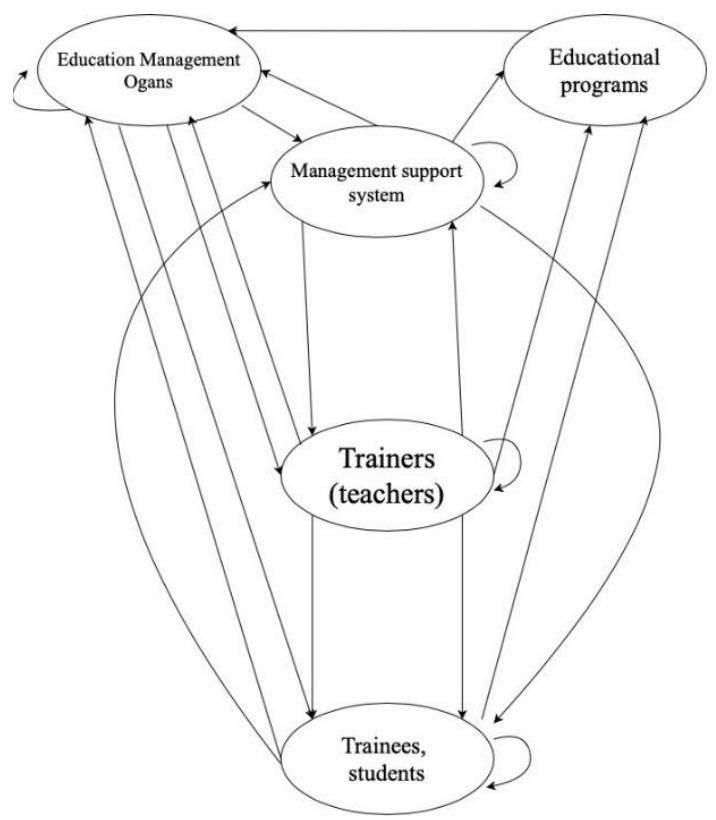

Fig. 1. Scheme of internal quality assessment of education. 
It is necessary to regularly examine all aspects of the life of a higher education institution - the quality of teaching, textbooks, and other teaching materials, the objectivity of assessment, the condition of classrooms, etc. - the so-called "internal quality monitoring". The analysis of such data will make it possible to judge the activities of teachers, administrators, technical services, and make appropriate management decisions on time. To implement internal quality monitoring requires the development of an appropriate standardized toolkit for different types and kinds of educational institutions.

\subsection{Assessment of educational programs}

The procedures and methods of quality assessment of educational programs in entrepreneurship are currently not well developed; a targeted development of appropriate methods and recommendations at the federal level is required, which will effectively carry out this work at every level of entrepreneurship education.

Self-scoring of educational institutions teaching entrepreneurship is currently practiced in part. It is advisable, based on in-depth analysis, to identify and disseminate the positive successful experience of universities in organizing self-scoring to educational institutions.

\subsection{Assessment of educational institutions teaching entrepreneurship by education authorities}

The mechanisms for this assessment are relatively fully developed but they require further improvement, primarily in terms of objectifying the relevant procedures, indicators, and criteria. This is evidenced by the dissatisfaction of consumers with the level of effectiveness of this type of assessment.

\subsection{Assessment of individual achievements of trainees}

At the level of an educational institution, the assessment of individual achievements of students, as a rule, is implemented within the framework of two procedures: State Final Certification of graduates and intermediate certification of students within the framework of the internal quality control system of entrepreneurship education.

Methodological toolkit for a quality assessment of the preparation of students/trainees of entrepreneurship education institutions in most constituent subjects of the Russian Federation is developing, as a rule, by the educational institutions themselves based on the relevant state educational standards, the assessment materials used are far from perfect.

There is a need for purposeful work at the federal level to form appropriate assessment materials, which should be unified.

In the current Russian practice, the quality assessment of the training of graduates, as the main component of assessing the performance outcomes of education institutions, is carried out by the manufacturers of educational services themselves. An exception is the assessment of the level of training of secondary school graduates, for which the mechanism of independent assessment has now been implemented for the first time within the framework of a Unified State Exam.

\subsection{Performance assessment of pedagogical staff}

The existing system of assessment (certification) of managers and teachers of educational institutions can currently be considered relatively satisfactory in comparison with other 
aspects of the quality assessment of education. In the medium term, it is necessary to develop and test new models for assessing the activities of pedagogical staff.

\subsection{Performance assessment of management bodies of entrepreneurship education}

Currently, the activities of the management bodies of entrepreneurship education are assessed only by the regional administrations or the government of the Russian Federation, depending on the subordination of the respective educational institutions and cannot be assessed by trainees, trainers, educational institutions, or external entities - industrial structures, public organizations, etc.

It is necessary to form the components of the quality assessment of the system of entrepreneurship education of specialists who could implement unified standardized approaches to the types of assessments that are transparent to public structures. At the same time, permanent mechanisms for the formation of reliable information flows should be developed.

According to modern requirements, the main features of the activities of higher institutions are:

- high level of training of specialists based on fundamental and applied research;

- the unity of educational and research activities;

- the presence of classical specialties concerning the priority professional orientation of educational activities;

- integration of education, science, and culture.

The success of such activities is directly related to the quality of the scientific and pedagogical staff of the institution, which should be dominated by persons with academic degrees and titles, as well as experience in the field of entrepreneurship.

Currently, a monitoring system the quality of entrepreneurship education is being formed in the country's higher educational institutions.

Monitoring is understood as a specially organized, permanently operating system of accounting (statistical reporting), collection, analysis, and dissemination of information, carrying out additional information and analytical surveys and assessment (diagnostics) of the state, development of trends, and severity of situations and specific problems.

The monitoring system of the quality of entrepreneurship education includes the interaction of subjects (external and internal) and objects (students, teachers, and the educational process itself) of monitoring.

The Ministry of Education of the Russian Federation and the relevant sectoral authorized structures carry out external monitoring by licensing the right to carry out educational activities in general and in specific specialties, as well as attestation of the institution and specialties with subsequent accreditation. Based on the monitoring results, the ministry, unilaterally or jointly with sectoral authorized structures, decides on the future fate of individual specialties and the institution as a whole.

Organizations employing graduates of higher institutions have certain requirements for the quality of training. This is reflected in specific applications indicating the qualification requirements for future employees, as well as in the fact that enterprise managers participate in the final certification of graduates of higher education institutions. Moreover, large enterprises that accept a large number of graduates periodically (for example, once every three years) submit to institutions of higher education an opinion on the quality of their work, which reflects:

- compliance with the requirements of the level of preparedness of specialists;

- promotion of specialists up the career ladder; 
- opportunities for further professional growth and development of the creative potential of specialists.

These conclusions are based, as a rule, on the results of certification of employees of the enterprise from among the graduates of the institution.

In more detail, the procedure for such certification approaches to the formation of its final conclusion is discussed below.

Internal subjects of monitoring include the management of the institution, its structural units; educational and methodological management; state certification commission.

The essence of the monitoring of quality assessment of entrepreneurship education is to conduct a comprehensive assessment of the performance outcomes of activities aimed at realizing human potential using education methods. Monitoring should be carried out taking into account the following basic principles:

- the comprehensiveness of the assessment, which ensures that all the most important components of the potential are taken into account, which can be realized based on the educational activities of the corresponding education institution;

- focus on the socio-economic development of economic sectors, administrativeterritorial entities, and specific enterprises based on a system of social indicators that characterize the development of infrastructure and its individual components of industrial facilities. Separate social indicators and/or groups of indicators make it possible to represent the state of different components of education;

- systematic assessment, which involves taking into account the interrelationships of basic indicators and the use of an ordered structure of private and integral characteristics of the state and development of the education sector and the economy sector interested in personnel training;

- ensuring the maximum representativeness of indicators for assessing various aspects of the state and development of the education system, as well as its objects - institutions;

- taking into account the reliability of the initial data when choosing indicators;

- adaptation of the indicators used to the capabilities of existing statistical reporting;

- compliance of the indicator system with the tasks of annual monitoring and forecasting the development of the industry;

- achieving maximum information content of the assessment outcomes from the standpoint of making adequate decisions at the federal, regional, sectoral levels of management;

- a combination of indicators with indices reflecting the performance of the authorities and in solving the most important problems related to the training of personnel and the structures authorized to solve them. 


\begin{tabular}{|c|}
\hline Collecting information from potential social customers \\
\hline She ratio of the selected variant to the available options \\
\hline Selection of control type (for process or for result) \\
\hline Definition of parameters for assessing educational outcomes \\
\hline Diagnostics of trainees' personality \\
\hline Prediction of educational outcomes for trainees \\
\hline Corsion statement of the school \\
\hline Identification of factors, preparation and implementation of the school development program \\
\hline Comparison of the obtained education outcomes with the set goals \\
\hline Defining educational quality \\
\hline Conformity of the educational quality with the set goal \\
\hline Ratio of the desired outcomes to the available outcomes and mode of life of the school \\
\hline
\end{tabular}

Fig. 2. Mechanism of education quality management.

This mechanism corresponds to the scientific and theoretical principles in the development of the definition of quality and is based on the approaches and principles described above. The quality management mechanism is universal, it allows one to determine the quality of entrepreneurship education at all levels of the educational process from the student to the administration of the educational institution.

Currently, the education system operates traditional methodological approaches that have developed over a long period to assessing the effectiveness of government and departmental decisions.

\section{Conclusion}

The information formed on their basis is of a general methodological nature, it does not contain criteria and social indicators, as well as indicators characterizing the creation and functioning of intellectual capital, which could be used as specific criteria and indicators for targeted monitoring, as well as for indicative planning in the field of training personnel based on a quality assessment of the results of training specialists for specific sectors of the economy, taking into account the technologies of strategic program and project transformations.

At the same time, it should be noted that the Ministry of Education and Science of the Russian Federation has developed criteria and indicators by which one can judge the realization of human potential by methods of education. They are acceptable enough for practical work and are publicly presented. However, their use is not methodically explained.

The set of criteria and indicators used in monitoring, according to the author, should:

- contain a limited number of criteria and indicators;

- reflect the relevant positions of the social and economic development of the industry;

- to be representative in the aspect that it is capable of reflecting the specifics of the industry and its enterprises, moreover, to carry out not only fixing the moment cut using static indicators but also the dynamics of the situation using indices (reflecting the deterioration or improvement of the situation);

- to be methodologically correct; 
- to be structurally consistent - without strong disparities in the number and quality of indicators for the selected items, which can be achieved through aggregation (formation of composite indicators).

An important aspect of building a system of criteria and indicators for assessing the effectiveness of activities focused on realizing human potential by methods of higher education is the standardization of indicators, which means the choice of a sample.

Thus, there is a need for a reasonable selection of indicators based on the federal, regional, sectoral, and international levels and regulatory documents related to assessing the development of entrepreneurship.

The criteria and indicators should provide a real possibility of monitoring, which implies a comparison of real indicators with a sample indicator. This allows one to determine the interval of change of a specific indicator (concerning the sample).

\section{References}

1. A. Misbakhova, A. Shinkevich, Y. Belozerova, G. Yusupova, L. Stakhova, Journal of Advanced Recearch in Law and Economics VII(2), 323 - 331 (2016)

2. M. Guerrero, D. Urbano, J. Cunning- ham, The Journal of Technology Transfer 39(3), 415-434 (2014)

3. A. Gibb, Opettajankouluttajien yhteistyöverkosto 3(23) (2018)

4. A. Chepurenko, O. Obraztsova, E. Popovskaya, Entrepreneurship in Transition Economies (Springer International, Cham, 2017).

5. M. Lacatus, Entrepreneurship in Education. International conference Knowledge-based organization (2016)

6. E. Lyapuntsova, Y. Belozerova, I. Drozdova, G. Afanas'ev, E. Okunkova, Journal MATEC Web of Conferences 251 (2018) DOI: https://doi.org/10.1051/matecconf/201825106032

7. E. Lyapuntsova, M. Vdovichenko, Yu. Belozerova, A. Gorbatov, MMCA2019. Conference 2019 The modeling and methods of structural analysis (Moscow State University of Civil Engineering, Moscow, 2019) DOI: 10.1088/17426596/1425/1/012165

8. E. Lyapuntsova, Iu. Belozerova, I. Drozdova, O. Korol, E3S Web of Conferences 97, 06034 (2019) DOI: https://doi.org/10.1051/e3sconf/20199706034

9. A. Naia, R. Baptista, C. Januário, V. Trigo, Journal of Entrepreneurship Education 18(1), 111-135 (2015)

10. V. Bolotov On the creation of an all-Russian system of education quality in the Russian Federation https://www.ast-centre.ru/poleznaya_informaciy/publikacii_statii/870/

11. V. Borkovskaya, E. Lyapuntsova, M. Nogovitsyn, E3S Web of Conferences 97, 06036 (2019) DOI: https://doi.org/10.1051/e3sconf/201997060

12. E. Efimova, Regional aspect: Sat. Art. int. scientific-practical conf. (Publishing house of NNSU, N. Novgorod, 2015)

13. N. Vasilenko, A.Ya. Linkov, Economics of education: textbook (INFA-M, 2017)

14. Z. Sultalieva, Bulletin of DSTU. Technical science 2 (2016) 